\title{
An Exploration in the language of Humor in English
}

\author{
Homa Mahna \\ Department of English Language, Islamic Azad University, Tabriz Branch, Iran \\ Tel: +98-914-306-5126_E-mail: hmahnah@gmail.com
}

Received: 26-06- 2012

doi:10.7575/ijalel.v.1n.6p.44
Accepted: 01-08- 2012

Published: 01-11- 2012

\begin{abstract}
The purpose of this study is to investigate why certain discourse textual maneuverings are perceived as humorous. The main focus is on the written forms of humor, precisely English jokes or word play which were analyzed in order to see how much humorous effect is created on the recipients through the violation of how many and what combinations of Gricean Maxims in these jokes. Being descriptive in nature, this research speculated on whether there are differences in the degree of humor among the three selected combinations of Gricean maxims. Through the analysis of selected data and checking their degree of humor on a few M.A students some results were obtained which show the similarities and differences in the degree of humor concerning the mentioned three different combinations. In conclusion, we found that these three various combinations of Gricean maxims have little humorous effect on the concerned-recipients.
\end{abstract}

Keywords: verbal humor, Gricean maxims, pragmatic jokes

\section{Introduction}

The central idea of this section is to elaborate on the relationship between humor and language. In fact, the emphasis is on the exploitation of language for the sake of laughter. So, the first part attempts to elucidate the relationships between humor and language and give a bird's eye view of the theories involved in this field. And the second part intends to focus on the well-known mode of verbal humor, in particular jokes.

\subsection{The Relationship between Humor and Language}

One of the numerous ways of provoking laughter is the use of language. However, in the world of verbal humor, language operates as mediator. According to Nash (1985:7), "Through form we come to language, the trigger that detonates the humorous mass. About its functions, two things may be noted at this point. One is that there is usually a centre of energy, some word or phrase in which the whole matter of the joke is fused, and from which its power radiates; and the other is that language of humor dances most often on the points for some dual principle, an ambiguity, a figure and ground, an overt appearance and covert reality."

As a matter of fact, nearly every component of our linguistic system can be exploited for the sake of laughter. To put it simply, language itself can be used for comical needs, by manipulation of its different fields and areas. So, language structures play a decisive role in the creation of ironic discourse. At this point, it is useful to give an overview of the research done in the field of verbal humor. The topic of humor has been approached by different scholars. In his book, Attardo (1994: 13) pragmatically defines humor as "a text whose perlocutionary, i.e. intended effect is laughter." This definition considers humor as a social phenomenon. In fact, it is possible to relate the above statement to the 'speech act' theory proposed by J. Austin (1962). According to the theory, words not only mean something, but also do something. In daily life, utterances perform three acts, one of which is perlocutionary act which is the effect created on the receiver. In this regard, "a witty story is also an utterance which bears in itself perlocutionary force. The act to which it tries to lead the listener is laughter"Culler (1982: 113).

In addition, Bruyn (1993) argues that "jokes are speech acts, acts of humor with perlocutionary effect in mind to amuse." Thus, verbal humor can be investigated in the domain of speech act theory. Let's consider the following example:

Clergyman: 'I now pwonounce you man and wife'.

Bride: 'And you pwonounce it beautifully, wector'. 
We might regard the mispronunciation in this joke because of the speech defect of both the clergyman and the bride. However, the most important point is that 'pronounce' does not mean 'the way I say these words', but rather, 'What I do with these words'. The bride, however, chooses to interpret pronounce in the former sense' Nash (1985:113).

Attardo (1994) elaborates on the various linguistic theories of humor that have been proposed, dividing them into four categories: structuralist, semiotic, sociolinguistic, and script based theories. In spite of having different stand points, they seem to cover a great deal of common ground.

The structuralist theories of humor are based on semantic component of a text which is basically polysemous and consequently ambiguous. According to Attardo (1994: 44), "To determine the sense of a text, a process of disambiguation takes place." He puts great emphasis on puns, which can be studied within the structuralist framework.

The inspiration for semiotic theories comes from Koestler's (1964) cognitive bisociation model, the key to humor production and reception. Scholars with a semiotic approach to humor research are Manetti (1976) and Eco (1986). The former believes in "the kind of contrasts between isotopes that are regarded as humorous within a given culture," and the latter wants to include "pragmatic competence such as conversational implicatures and intertextuality into humor research" (Attardo 1994: 180). Both of them have applied Grice's cooperative principle to humor research. The sociolinguistic theories of humor apply conversation analysis to humor research. The analysis of verbal humor is situated within a framework which views language as a socio-semiotic system (Halliday 1978). Humor potential at language user's disposal is determined by the specific options of the socio-cultural system into which they have been socialized (Alexander 1993).

According to Attardo (1994: 195), "the script based theories of humor originated within the field of generative grammar." The most prominent among these is the 'Semantic Script Theory' proposed by Raskin (1985: 99). He claims that "a text can be characterized as a joke if both of the following conditions are satisfied: (1) The text is compatible, fully or in part, with two different scripts, (2) The two scripts with which the text is compatible are opposite in a special sense." In this regard, Raskin's prototypical joke is:

"Is the doctor at home?" The patient asked in his bronchial whisper.

"No," the doctor's young and pretty wife whispered in reply. "Come right in."

So, according to Raskin (1985), "the above joke is compatible with the two scripts 'doctor' and lover and the scripts are opposite on the sex vs. non sex basis"( Ruch 1998).

With an interest in pragmatics, Raskin (1985: 100) also discusses what he calls non bona fide mode of communication. According to him, "non bona fide (i.e.) humorous communication differs from bona fide (i.e. earnest, serious Information conveying) communication in the way it violates one or more of the four conversational maxims of Grice's (1975) Cooperative Principle." These maxims, defining the bona fide mode of communication, are quantity, quality, relation, and manner .Obviously, to make something funny, communicational patterns have to be violated. Therefore, from a semiotic and pragmatic standpoint, humor is caused by a special treatment of the information, violating or infringing the rules of communication. "Not surprisingly, the humor of psychological and social satire is expressed to a very great extent through the flaws and missed connections of speech acts, the contractual failures of parties to conversation" Nash (1985: 116).

\section{Characteristics of Verbal Humor}

In the light of these preliminary discussions, we find out that verbal humor must have some fundamental principles, namely, linguistic ambiguity, which is a word or phrase with two or more possible meanings. The main source of ambiguity is, in fact, the absence of one-to-one correspondence between form and meaning or form and function. So, the ambiguity of a word/phrase allows us to interpret it in two or more possible ways and then it leads us to a humorous situation. Needless to say, one of the characteristics of a funny story is linguistic ambiguity, that is, a common way to create incongruity and potential resolution. Therefore, the emphasis is on the linguistic ambiguity which paves the ground for incongruity. In this regard, Haff and Kline (1993) argue that 'jokes operate in the domain of incompatibility.'

There is a linguistic classification for wit-producing ambiguities by Shultz and Pilon (1973) (as cited in Pepicello and Weisberg, 1983). Let us consider the following joke as an example;

A: Why did cookie cry?

B: Because its mother had been a wafer so long. 
In this example, incongruity is created by the phonological strings, and recognition of ambiguous phrase leads to the resolution of this incongruity. So it has two different underlying structures:

$$
\begin{aligned}
& \text { [a way }+ \text { far }] \\
& \text { [a + way far }]
\end{aligned}
$$

According to Pepicello and Weisberg (1983: 59), "First we interpret the ambiguous phonological string as `a wafer' and this produces incongruity that's resolved by reinterpreting the string as 'away for."

In fact, we observe that phonological, morphological, and syntactic categories can be manipulated to produce ambiguity, and consequently a humorous discourse. For instance, the use of word 'look' with a semantic ambiguity, in the following joke, provokes the laughter;

A doctor visits a sick woman and says quietly to her husband: "She does not look good to me." "You are telling me," says the husband: "She hasn't looked good to me for 20 years!"

The verbal form of humor particularly has an incongruity resolution structure. In fact, humor depends on the resolvable incongruity. So if the incongruity is removed from a joke or it is not resolvable, the joke should not be funny. Let's consider the following joke as evidence;

"Doctor, come at once! Our baby swallowed a fountain pen!"

"I'll be right over." "What are you doing in the meantime?" "Using a pencil."

As it is remarkable, 'Using a pencil' is incongruous, and this gives us a pleasure. If we substitute it with 'we don't know what to do', this would be congruous, and thus not laughable (incongruity removed version of the jokes). On the other hand, if we use 'a rubber band' for 'a fountain pen' (resolution removed version), there is still an incongruity. But there is no resolution because a 'pencil' cannot substitute for a 'rubber band' (This discussion is based on Suls (1985:45) (as cited in McGhee and Goldstein).

The above discussion reminds us of the fact that language is a two level system of syntagmatic and paradigmatic relations. According to lyons (1981: 96), "The former are the relations that hold among elements that can occur in combination with one another, in well-formed syntagms; the latter are relations that hold among sets of intersubstitutable elements at particular places in syntagms."

This distinction between syntagmatic and paradigmatic relations relies on the fact that the former is visible in the utterance, whereas the latter is evoked in the mind of the language user. However, these two concepts interestingly play an important role in the creation of humorous text. According to Nash (1985: 127), "Often the humorous characteristics of a phrase or sentence are both syntagmatic and paradigmatic." Thus we can claim that words and phrases seem funny because of the syntagmatic versus paradigmatic relationships. We assume that properties of humorous expression are defined extrinsically. Some of the defining features are syntagmatic, appearing in the repetitions, parallels, inversion, etc, marked out in the linear progression of the text. Others can be described as paradigmatic, being selections from a 'zone of choice' or implied set of possibilities e.g. a group of synonyms.' The defining features occur both in the line and the zone of the text. And the joking locus has its relationship to the line and the zone Nash (1985). Also, the following figures presents these relations;

Syntagmatic:Text:

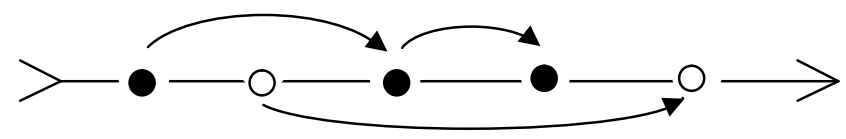

Paradigmatic:Text:

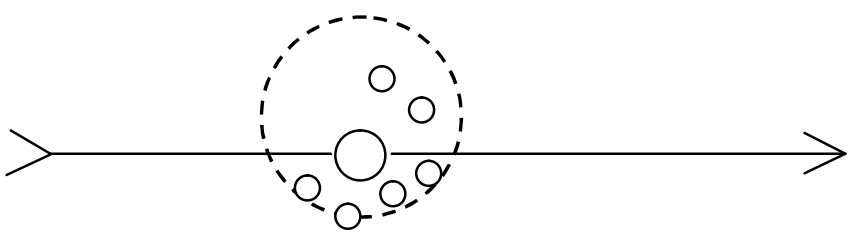

Text:



Zone 1

Zone 2 
In the light of the above comments, Chiaro (1992: 34) claims that "when the wrong filler (accidentally or otherwise) is placed in the wrong slot, the paradigmatic invades the syntagmatic." In addition, she refers to Sherzer (1978), who describes pun as 'a projection of the paradigmatic onto Syntagmatic,' rejecting the so-called definition of a pun, that is, a word with two meanings.

\section{1 Joke as a well known Mode of Verbal Humor}

There are various genres of linguistic humor, such as joke, riddle, pun, conundrum and enigma, which are totally labeled as 'word play'. Although the forms of these types of verbal humor vary considerably, they are almost used interchangeably. In fact, it is acknowledged that there is a subtle distinction among them, which falls beyond the scope of our study. Since joke has been received the most attention in the field of verbal humor, the main focus of this study lies on the joke analysis. Joke theories are as old as language philosophy; in a way both of them were the concern of Greek philosophy in the past. But, today, jokes as a form of non serious discourse are the concern of linguistics as well. In this regard, it is possible to explain the humorous effect of jokes from the linguistic point of view. According to Hockett (as cited in Chiaro, 1992: 34), jokes can be defined a "layman's poetry: variety of options within the language at his or her disposal with which to create a certain effect."

As a matter of fact, jokes are not only meant for the sake of fun, but can also be used for serious linguistic investigations, through which we can penetrate into depths of the English language. So, it is worthwhile to step on that unstable path.

Generally speaking, jokes do have different shapes and sizes, ranging from short (one line) to very long (shaggy dog story). They may be either simple or compound in terms of various combinations. Jokes universally cover the different topics in the field of human life, and they amazingly do their functions in the light of the pleasure. For instance, a joke with aggressive function, gives the recipient a feeling of superiority. There are various kinds of social jokes, concerning the individuals' character or occupation, such as children, doctors, policemen, lawyers, and so forth.

These units of discourse consist of two components; a build up (forming the expectations) and a punch line, which is the source of humor because it mainly possesses elements of surprise (give rise to surprise). As Ziv (1984: 90) states: "Every joke must have a punch line, a point of climax that is quickly over." Shakespeare knew it; he wrote in Hamlet that brevity is the soul of wit. The length of the joke itself does not matter, but the actual funny part must be short.

The so-called punch line is rather labeled as 'a locus' by Nash (1985:10). He defines 'a locus' as "some word or phrase that is indispensable to the joke; the point at which humor is held and discharged." Or "there is usually a centre of energy, some word or phrase in which the whole matter of the joke is fused and from which its power radiate."

In addition, Chiaro (1992: 20) attempts to define the punch line as follows: "The punch is the point at which the recipient either hears or sees something which is in some way incongruous with the linguistic or semantic environment in which it occurs but which at first sight had not been apparent. The punch is the pivot around which joke is centered. Even if the joke is not particularly good one, the anticlimax of the punch itself will be sufficient to create a feeling of surprise. It is the very mixture of expectancy and surprise which makes up the punch line." However, she puts emphasis on the fact that the punch line frequently relies on breaking the linguistic expectations of the recipient (listener / reader).

On the other hand, she points to the element of surprise, which is always present in the punch line. In fact, the element of surprise, caused by condensation of several meanings in the punch line, is the basic constituent of the joke. Surprise is necessary, but not sufficient indeed. There is no laughter without surprise. Not every surprise leads to the laughter, in a sense; the surprise should not be threatening. As Ziv (1984) argues frustrated expectation may arouse indifference, anger, or fear. We all know that there are plenty of unpleasant surprises in life, and they are not funny. So, in his view, the surprise should not be threatening and in some way bound up with the context of the joke. However, there is some kind of logic involved in this connection that is called 'Local Logic.' According to Ziv (1984:89), 'In every form of humor the audience is led in a certain direction and encouraged to form certain expectations and these are then turned upside down. Local Logic is appropriate in a way, because it brings some kind of expectation to the incongruity. We wait for one thing and get another thing, that is quite different, but that nevertheless has certain suitability." In order to clarify thoroughly, let us consider the following example: 
A young man looking for a wife went to a computerized marriage agency, filling out the form, he wrote, 'I'd like someone who likes lots of company, water sports and formal dress, and is preferably rather short'. The agency sent him a penguin! Extracted from Ziv (1984)

In this joke, if the marriage bureau were to have sent the young man a horse, that would be surprising, but not funny. According to Ziv (1984) "sending a penguin does seem funny; although it is not at all what he is expecting, it, in fact, fits all his requirements all but one, which he does not write down, and which is perfectly evident to us as well."

There are two aspects of joke design; 'the narrative shape' and 'Locative formulae,' 'One having to do with the method of extended narration, the other with the construction of witticisms in formulaic patterns' Nash (1985: 27).The former involves the 'shaggy dog stories,' while the latter deals with micro forms of jokes, namely, one liner, two liners, etc. A common form of narrative regarding jokes displays an explicit problem, and then a resolution for the problem. The problem solution pattern can be presented as;

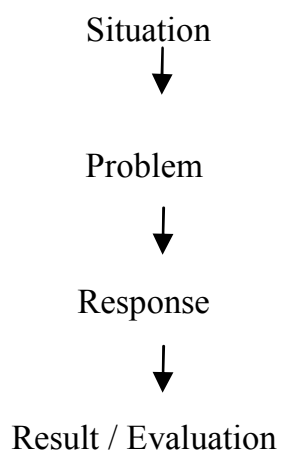

Taken from Chiaro (1992)

The following example precisely presents this type of joke;

There was a Scotsman, an Italian and Irishman. They wanted to watch the Olympic Games but they didn't have tickets, so they decided to go as athletes. The Scotsman pulled a bollard out of the ground, put it over his left shoulder, went to the ticket office and said: 'Jock McTavish, Scotland, and Caber Tossing'. And in he went. The Italian found an empty plate, put it under his left arm, went to the ticket office and said: 'Giovanni Bianchi, Italy, Discus Throwing'. And in he went. The Irishman scratched his head and thought. Then he put some barbed wire under his left arm, went to the ticket office and said: 'Paddy Murphy, Ireland, and Fencing'. Extracted from Chiaro (1992:49)

As it is evident (in the above joke) "the previous phases in the narrative form, are symmetrically constructed, Where as the last part is asymmetrical which has no counter move" Nash (1985:29).And the latter is "Locative formulae" According to Nash (1985), there is a formula which consists of two components; 'location' and 'prelocation / collocation.' The former refers to 'a phrasal sitting of the locus.' And the latter consists of three parts; the first part concerns 'a preparation of the discharge of the joke,' the signal by which a joke is intended. In fact there are forms of words that warn us of the advent of a joke, in other words, jokes are often announced. This announcement is called a 'signal', which is indispensable and takes various forms, e.g. 'Have you heard this one?' 'That reminds me ....., 'A funny thing happened,' etc. It may be a tag of the kind that is always recognized as introducing a funny story or a humorous observation (e.g.) the propositional question, 'Did you hear the one about ...?', or existential opening 'There's this fellow...; it may be the question that forewarns of a riddle, ' What's a ....?,' 'How do you ....?,' 'How many ...?', 'Where do ...?'. It may be an echo of the Cliché-imperative. 'Be x, Do y.' Nash (1985: 34).

So the importance of signaling relies on the intention of the sender to joke. In deed, it gives some readiness to the recipient that something funny is coming. The second part is 'an orientation', which indicates to the belonging of the joke to a thematic types, e.g. joke will be 'banana' joke, 'waiter' joke, 'elephant' joke, etc. And the third part includes the context which refers to the relevant background to the joke. It can be expressed either verbally or extra linguistically (the defined and implied context). In the construction of a formulaic joke, two elements are obligatory; the signal and the 'locus.'

According to Pepicello and Weisberg (1983), the most prominent and well known array of humorous strategies playing on linguistic structure is found in Hockett (1977). His concern is both the external and internal linguistic 
structures of humorous genres. The former is based on the bipartite structure of the joke, which consists of a build up and a punch line (mentioned before). And concerning the latter, Hockett divides word play into two broad categories: He distinguished two types, 'Prosaic' and 'Poetic' jokes. Prosaic jokes do not involve linguistic manipulation per se, but play rather upon cultural situations, interactions, and institutions. Poetic jokes, on the other hand, involve what Hockett called 'accidents in the design of English,' by which he meant humor based on grammatical forms and their usage or misusage. Pepicello and Weisberg (1983: 64)

So, prosaic jokes simply play on some aspects of the world knowledge, whereas poetic jokes simply play with language. For Hockett, poetic jokes fall into two types: puns and non puns, puns may be perfect (involving homophony) or imperfect (involving near homophony). Hockett's poetic category also contains what he terms non puns, e.g. the word reversal. From his point of view, poetic jokes are non translatable, since they are dependent upon grammatical categories of (in this case, English language) related language. Despite the above comments, Chiaro (1992) hardly believes that some kinds of jokes only concern the world knowledge and the other kind's concern linguistic knowledge. She consequently argues that "it seems a contradiction in terms to suggest that the joke doesn't in some way play on words. Any joke, whether it contains a pun or not, by the very nature of its verbalization, necessarily plays on language." Chiaro (1992:15)

According to Chiaro (as cited in Gusheva 1998), many jokes have a mixture of both 'verbal' (linguistic) and 'referential' (cultural) elements. In fact, both verbal and referential knowledge are needed to comprehend a joke. In order to be straight forward, let us consider the following two examples: (Extracted form Gusheva, 1998).

(1) What'd the astronomer say when asked about the possibility of Earth Being hit by an extraterrestrial object? No comet.

(2) Beauty is in the eye of the beerholder.

It is possible to argue that appreciation of these two jokes involves not only the verbal but also the referential knowledge. The first concerns the referential aspect, that is, people interviewed by the media say 'No comment' in some circumstances. And the second joke reveals the fact that consumption of beer affects the judgment.

There is no situation that is always funny for everybody, and this reminds us of the fact that humor depends on one's historical, social, cultural, and national background. So something that is funny for one person may be quite illogical for another. Overall people enjoy different forms of humor, because their needs differ, that stem from their personality. According to Mills (1995), Our reasons for Laughing or not laughing at particular situations, are governed to a large extent by our own background, our societal and cultural expectations, or on how we perceive ourselves to be in relation to the rest of society.

Concerning the different ways, nations respond to jokes and bearing in mind their mentalities, Bergson (1975) states: "The English laugh three times, first of politeness, then when the joke is explained to them, at the end when they understand the joke, Germans laugh twice; first of politeness and then when the joke is explained to them because they will never understand it. The French laugh once, because they understand everything right away, whilst the Americans never laugh, because they have already heard the joke" (cited in Krushink 1959:73).

According to Ziv (1984: 111) there are two dimensions of humor; humor creativity and humor appreciation. The former is "the ability to perceive relationships between people, objects or ideas in an incongruous way, as well as the ability to communicate this perception to others." And the latter is "the ability to understand and enjoy messages containing humor creativity, as well as situations that are incongruous but not menacing." In the domain of humor, sex difference is also remarkable in away that men are better at creating humor, and women at enjoying it. But it does not imply that all males are more creative than females. Female enjoyment arises from the fact that emotional expression in our society is assigned to women rather than to men. It is possible that both sexes in fact enjoy humor to the same degree, but that women are more prepared to show it by laughing.

Generally speaking, the concept of shared knowledge is necessarily considered as a vital element in humor appreciation. As we leave the world of wordless humor and enter the world of verbal humor, a joke will be non-joke due to the lack of cultural/shared knowledge, between the sender and the recipient. As Chiaro (1992:11) points: "If word play is to be successful, it has to play on knowledge which is shared between sender and recipient."

In deed, if we are to find a joke meaningful, we should know about the cultural and social facts, about shared beliefs and attitudes, and even about the pragmatic bases of communication. According to Nash (1985:9), "We share our humor with those who have shared our history and who understand our way of interpreting experience." 
In this regard, Chiaro (1992) insists on the role of the world knowledge in humor enjoyment, when she claims that linguistic competence is the least element that the recipient needs to know: Recognition of language is the lowest common denominator required for the comprehension of a joke, this recognition appears to include a large amount of sociocultural information which should also be in their possession.

Thus, the recipient should easily recognize the instances of broken linguistic rules. According to Chiaro (1992:13), "his / her (recipient) linguistic knowledge requires a high standard of proficiency to be able to deal with the ambiguities and hidden traps of, in this case, English Language." Therefore, if someone does not get a joke, this will be due to the lack of shared knowledge, and linguistic knowledge as well. We can thus say that three systems interact with each other in order to make up the sort of competence required in order to get a joke, 'Linguistic, Socio-cultural and poetic.' Rechard Alexander (1982) defines poetic competence as the ability to recognize the ways in which linguistic options can be maneuvered in order to create a desired effect - the recipient of a joke, in a sense, is in a similar position to the reader of poetry: "both needs to appreciate exactly how the comic/poet has toyed with language." Chiaro (1992: 13)

On the other hand, the psycholinguistic studies of humor have been concerned exclusively with humor appreciation. In general, psycholinguistic analysis of jokes has been based on the notions of incongruity and resolution. According to this view, "A situation is perceived as humorous if (a) the perceiver detects an incongruity in the situation (e.g.) the situation in some way violates the persons expectations, which surprises, perplexes, or arouses the person) and (b) the person is able to resolve the incongruity, so that - the situation is seen to be sensible when viewed in the appropriate way. This resolution is assumed to reduce the arousal produced by initial perception of incongruity, and such, decreases in arousal are seen as pleasurable." Berlyne (1972) (as cited in Pepicello and Weisberg, 1983:73)

With an interest in psychology, Ziv (1984) suggests a cognitive - emotional model for the comprehension and enjoyment of humor. From his point of view, this model is intended to explain our enjoyment of not only jokes, but also cartoons and humorous remarks. This model consists of six main stages, which can be summarized as follows:

1. Preparation: This stage likely deal with the signal of a joke, in a sense, it adds to the readiness of the recipient by creating right atmosphere. According to Ziv (1984: 93), "it signals to the listener that a funny message is coming and one should change from seriousness to playfulness." There are some factors involved in this stage, such as social situation, humorous image of speaker, comic appearance, facial expression, and verbal declaration. 2. Content of Joke: The content of joke concerns the three parts that the most jokes have been built upon, namely, "the establishment of the background, a story that leads the listener in a certain direction, and the punch line" Ziv (1984: 93). 3. Tension and Violation of Balance: Ziv (1984) states that we feel discomfort by encountering an incongruity, and thus become surprised. And then in the cognitive process, we try to understand the humorous message by solving the incongruity, and consequently resorting balance.4. Cognitive Process: But what happens in our minds when we hear / read the punch line of joke? In the following, Ziv (1984) sheds light on the problem: First of all, we feel that there's something wrong here. We have expected one thing and have found another, we are accustomed to logical thinking, and all of a sudden it does not work. Failing to solve a joke's incongruity by logic, we try the thought mode of local logic. It is possible to argue that the recipient should move from seriousness to playfulness and thus find a solution for the presented incongruity. In a sense, if we stay with ordinary logic, we will not understand the joke. 5. Cognitive Enjoyment: This stage of the model is the feeling of satisfaction that comes from resolving a joke's incongruity. "Basically, it is a release from tension, and it finds physiological expression in laughter." Ziv (1984:96) 6. Functional Enjoyment: This stage reveals the fact that a joke would accomplish a specific function for the recipient. "Functional enjoyment derives from the pleasure that a joke gives by fulfilling a specific functional for the listener" Ziv (1998:96). According to Ziv (1982), in most forms of humor, our laughter has a double source, arising both from cognitive and from functional enjoyment.

\section{Methodology}

\subsection{Introduction}

The thrust of this descriptive research is to focus on the language of humor, in particular verbally expressed humor. In fact, we tend to enter into the world of pragmatics, and consequently deliberate flouting of Gricean Maxims which occurs in such special cases as sarcasm or joking. So, our attempt is to investigate how much humorous effect is created through the violation of two or more of Gricean maxims in pragmatically-based jokes. 
In what follows we will focus on the pragmatic jokes as the material of this study, and then discuss the procedures related to both the selection of subjects and materials. In the phase of data analysis, a few jokes will be analyzed on the basis of the research question. Finally, the results and discussions will be presented.

\subsection{Materials}

Presumably, there are two broad categories of jokes based on Hockett's (1977) distinction. In fact, he distinguished between two types of jokes:

Poetic jokes and Prosaic jokes. The former involves what Hockett called 'accidents in the design of English,' by which he means humor based on grammatical forms and their usage or misusage. And the latter plays rather upon world knowledge or cultural situations. So some jokes make us laugh because of the exploitation of grammatical forms. But there are jokes which create humorous effect by going through the field of pragmatics. Building on this background, there are two kinds of jokes: linguistically-based jokes which play on grammatical forms, and pragmatically-based jokes which concern the world knowledge/pragmatics. However, our category is the pragmatic jokes concerning the cooperative principles proposed by Grice (1976). Having read plenty of jokes from different sources, we did the categorization of pragmatic jokes in terms of the number and the combinations of maxims which are violated to produce humorous effect. As we found out there are the violation of various combinations of maxims involved in these jokes. And here our attempt is to illustrate some of them and to verify their humorous effectiveness. In this respect, we have selected three combinations of maxims as follows:

(1) Quantity, Relevance, Manner

(2) Quality, Relevance, Manner

(3) Relevance, Manner

From each subcategory, we picked up 5 social jokes with an interactive genre, and then checked their degree of humor by testing them on the subjects to see which one of the above combinations leads to more effective humor, (15 jokes will be included in the Appendix B).

\subsection{Subjects}

In the selection of subjects, we have considered the following factors; Age, Gender, MT, SL, FL. and we also provided them with a questionnaire to distinguish the Extroverts from the Introverts, as the social dimension is the most decisive factor in humor enjoyment. In a sense, the Extroverts enjoy humor more than the Introverts. So, from many MA students we only picked up 8 Extroverts, whose scores ranged from 5 to 10 concerning the Extroversion Introversion questions. Then, the background information about the subjects was probably controlled with regard to the following factors;
(1) MA students
MT: Azerbaijani
(2) Age: $25-30$
SL: Persian
(3) Gender: Female FL: English

However, we provided the subjects with the 15 jokes and asked them to subjectively express how much humorous they found them, going through the five-point scale on their answer sheet.

\subsection{Data Analysis}

Concerning each subcategory, the analysis of a few tested-jokes is presented as follows;

a) The Example of the first subcategory; (1) Quantity, Relevance, Manner.

Visitor Boy: "How old are you, Sonny?"Boy: "That's hard to say, Sir. According to my Latest school tests, I have a Psychological age of 11 and a moral age of 10. Anatomically, I'm 7, mentally, I'm 9. But I suppose you refer to my chronological age. That's 8 - but no body pays any attention to that these days!"

In this joke, we regard the violation of Quantity and Relevance Maxims because 'the boy' gives more information than is required, and thus this information seems irrelevant to the question being asked by the 'visitor.' Also the Maxim of Manner is violated as Chiaro (1992) argues that 'all jokes are ambiguous.'

b) The Example of second Subcategory; (2) Quality, Relevance, Manner.

-"It was so cold where we were," boasted the traveler who just returned from Alaska, 'That the candle froze and we couldn't blow it out'."That's nothing," said his rival, "Where we were, the word came out of our mouths in pieces of ice, and we had to fry them to see what we were talking".

As it is evident in this conversation, the second speaker violated the Quality and Relevance Maxims, by stating the utterances that are not true, and in fact the second speaker didn't give the right information. Accordingly Attardo (1994) points 'if two maxims were violated in a joke one was the maxim of relevance, but if only one was, then it was relevance'. 


\section{International Journal of Applied Linguistics \& English Literature \\ ISSN 2200-3592 (Print), ISSN 2200-3452 (Online)}

Vol. 1 No. 6; November 2012

c) The Example of the Third Subcategory; (3) Relevance, Manner

Customer: "Have you a book called 'Man, the Master of Women'?"

Salesgirl: "The fiction department is on the other side, Sir.

In the above joke, the Salesgirl violates the Maxim of Relevance as her response is not related to the customer's question.

\section{Results and Discussions}

As it is mentioned, there is a five point scale which shows the degree of humor in a joke (Completely presented in the appendix $\mathrm{C}$ ). Thus specific score is given to for every scale as follows:

Very much $=10 \quad$ Much $=8 \quad$ Some $=60 \quad$ Little $=40 \quad$ No Humorous $=20$

In this respect, the results are presented concerning each subcategory as follows:

Table1(1).Quantity, Relevance, Manner

\begin{tabular}{|c|c|c|c|c|c|}
\hline Soke No & 1 & 2 & 3 & 6 & 9 \\
\hline 1 & 40 & 80 & 60 & 80 & 80 \\
\hline 2 & 60 & 80 & 60 & 80 & 80 \\
\hline 3 & 60 & 60 & 80 & 100 & 60 \\
\hline 4 & 60 & 40 & 40 & 60 & 60 \\
\hline 5 & 60 & 60 & 80 & 80 & 40 \\
\hline 6 & 40 & 60 & 80 & 60 & 60 \\
\hline 7 & 60 & 80 & 80 & 80 & 100 \\
\hline 8 & 60 & 80 & 100 & 80 & 100 \\
\hline
\end{tabular}

Table 2. (2).Quality, Relevance, Manner

\begin{tabular}{|c|c|c|c|c|c|}
\hline S No No & 4 & 8 & 11 & 12 & 13 \\
\hline 1 & 80 & 80 & 80 & 80 & 100 \\
\hline 2 & 80 & 60 & 40 & 40 & 80 \\
\hline 3 & 80 & 100 & 60 & 80 & 100 \\
\hline 4 & 100 & 60 & 60 & 60 & 60 \\
\hline 5 & 40 & 40 & 20 & 40 & 20 \\
\hline 6 & 80 & 40 & 80 & 40 & 60 \\
\hline 7 & 100 & 80 & 80 & 100 & 100 \\
\hline 8 & 60 & 60 & 60 & 60 & 60 \\
\hline
\end{tabular}

Table 3. (3). Relevance, Manner

\begin{tabular}{|c|c|c|c|c|c|}
\hline $\mathrm{S} \mathrm{No}_{\mathrm{S}}^{\text {Joke No }}$ & 5 & 7 & 10 & 14 & 15 \\
\hline 1 & 80 & 60 & 100 & 80 & 60 \\
\hline 2 & 80 & 60 & 60 & 60 & 80 \\
\hline 3 & 60 & 100 & 60 & 60 & 40 \\
\hline 4 & 80 & 80 & 60 & 40 & 100 \\
\hline 5 & 80 & 20 & 40 & 20 & 60 \\
\hline 6 & 100 & 60 & 60 & 60 & 60 \\
\hline 7 & 80 & 80 & 100 & 100 & 60 \\
\hline 8 & 80 & 60 & 80 & 80 & 60 \\
\hline
\end{tabular}




\section{International Journal of Applied Linguistics \& English Literature}

ISSN 2200-3592 (Print), ISSN 2200-3452 (Online)

Vol. 1 No. 6; November 2012

In order to find the percentage of each scale, we have used the relative frequency which refers to the frequency of each score divided by the total number of scores. Here, the total number of scores is 40 . Thus, the relative frequency and the percentage of each scale can be presented as follows:

Pattern 1:

\begin{tabular}{lllll}
\hline \multicolumn{3}{c}{ Relative Frequency } & Percentage \\
\hline Score & Frequency & Compute & Result & \\
\hline 100 & 4 & $4: 40$ & 0.1 & $0.1 \times 100=10$ \\
80 & 16 & $16: 40$ & 0.4 & $0.4 \times 100=40$ \\
60 & 15 & $15: 40$ & 0.375 & $0.375 \times 100=37.5$ \\
40 & 1 & $1: 40$ & 0.025 & $0.025 \times 100=2.5$ \\
20 & 0 & 0 & 0 & 0 \\
\hline
\end{tabular}

In this pattern (1), we observe the percentage of each scale is:

$\begin{array}{ll}10 \% & \text { Very Much } \\ 40 \% & \text { Much } \\ 37.5 \% & \text { Some } \\ 2.5 \% & \text { Little } \\ 0 \% & \text { No Humorous }\end{array}$



Pattern 2:

\begin{tabular}{lclll}
\hline \multicolumn{5}{c}{ Relative Frequency } \\
\hline Score & Frequency & Compute & Result & \\
\hline 100 & 7 & $7: 40$ & 0.175 & $0.175 \times 100=17.5$ \\
80 & 12 & $12: 40$ & 0.3 & $0.3 \times 100=30$ \\
60 & 12 & $12: 40$ & 0.3 & $0.3 \times 100=30$ \\
40 & 7 & $7: 40$ & 0.175 & $0.175 \times 100=17.5$ \\
20 & 2 & $2: 40$ & 0.05 & $0.05 \times 100=5$ \\
\hline
\end{tabular}


International Journal of Applied Linguistics \& English Literature

ISSN 2200-3592 (Print), ISSN 2200-3452 (Online)

Vol. 1 No. 6; November 2012

So in this pattern (2), the percentage of each scale is:

$\begin{array}{ll}17.5 \% & \text { Very Much } \\ 30 \% & \text { Much } \\ 30 \% & \text { Some } \\ 17.5 \% & \text { Little } \\ 5 \% & \text { No Humorous }\end{array}$

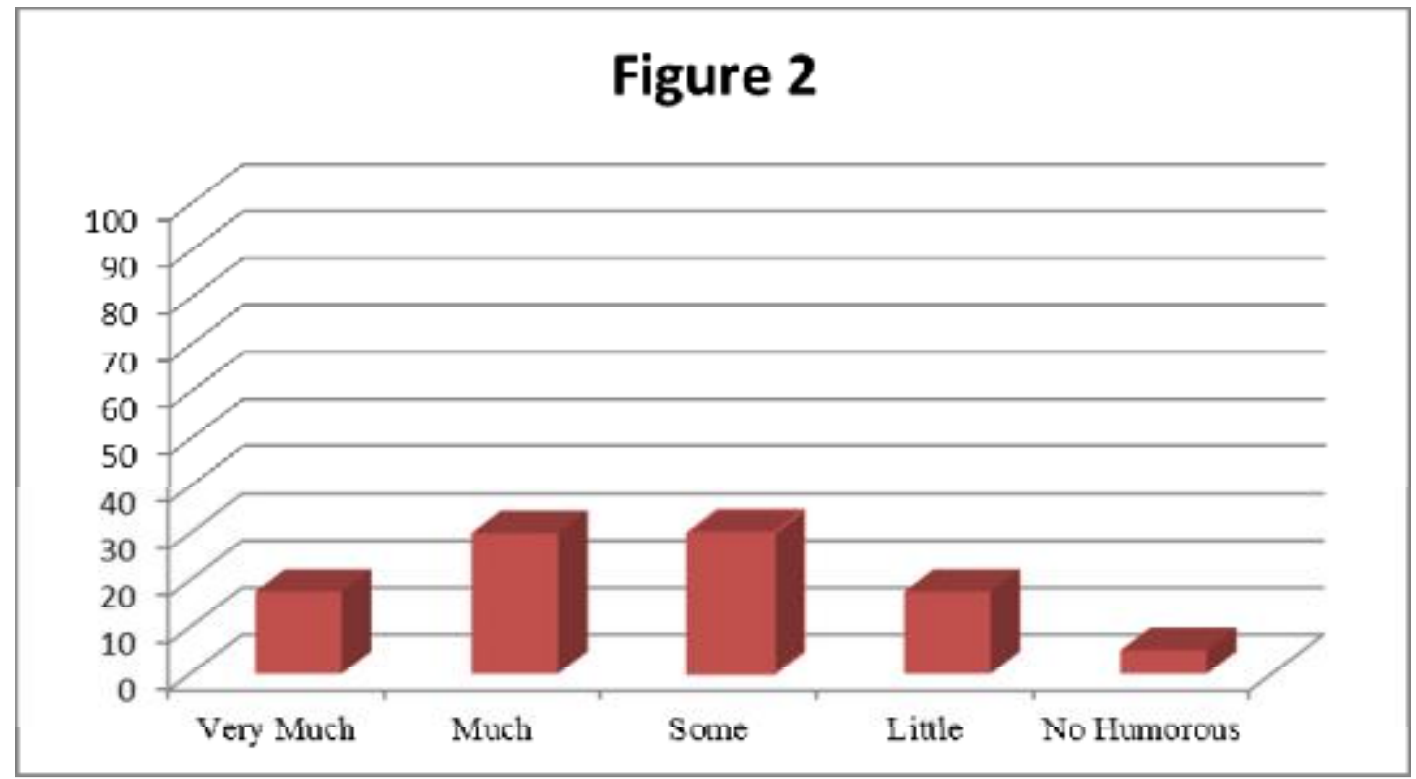

Pattern 3:

\begin{tabular}{lclll}
\hline \multicolumn{4}{c}{ Relative Frequency } & \multicolumn{2}{c}{ Percentage } \\
\hline Score & Frequency & Compute & Result & \\
100 & 7 & $7: 40$ & 0.175 & $0.175 \times 100=17.5$ \\
80 & 12 & $12: 40$ & 0.3 & $0.3 \times 100=30$ \\
60 & 16 & $16: 40$ & 0.4 & $0.4 \times 100=40$ \\
40 & 3 & $3: 40$ & 0.075 & $0.075 \times 100=7.5$ \\
20 & 2 & $2: 40$ & 0.05 & $0.05 \times 100=5$ \\
\hline
\end{tabular}

Finally the percentage of each scale in patter (3) is:

$\begin{array}{ll}17.5 \% & \text { Very Much } \\ 30 \% & \text { Much } \\ 40 \% & \text { Some } \\ 7.5 \% & \text { Little } \\ 5 \% & \text { No Humorous }\end{array}$


International Journal of Applied Linguistics \& English Literature

ISSN 2200-3592 (Print), ISSN 2200-3452 (Online)

Vol. 1 No. 6; November 2012

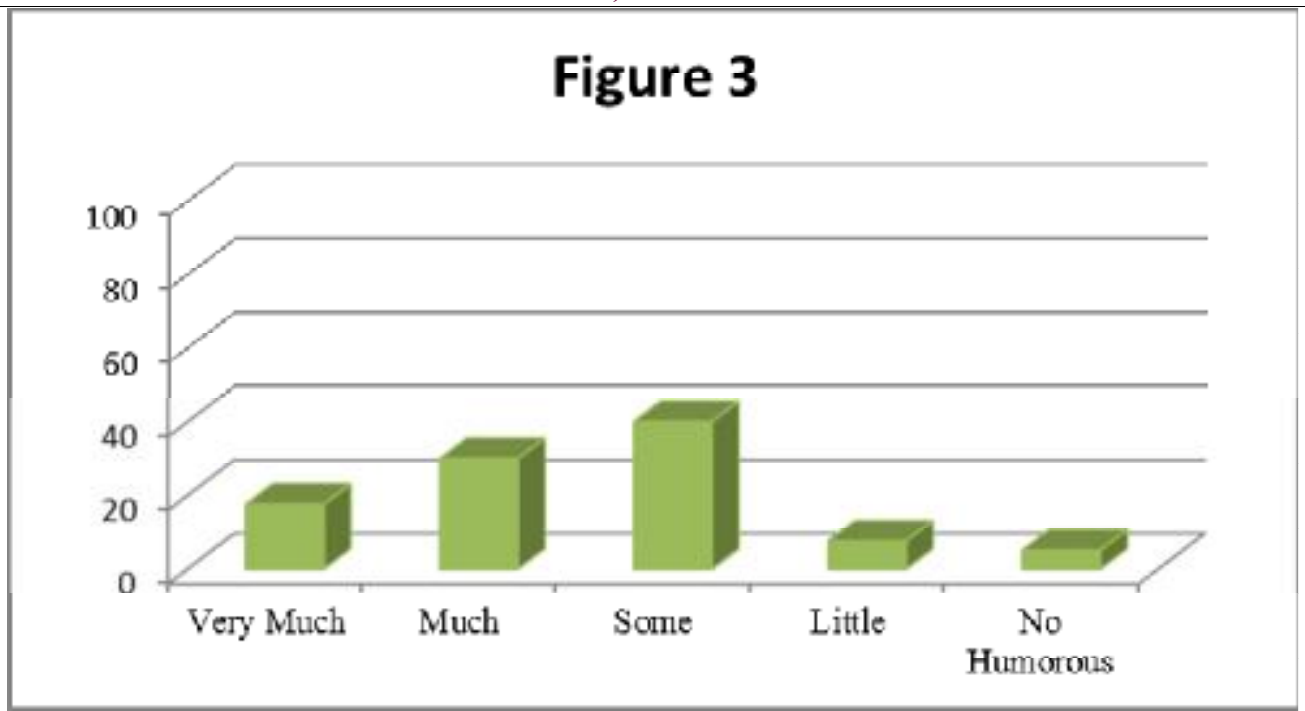

In the following figure, the three different combinations of maxims are compared in terms of each scale.



In the following figure, the three different combinations of maxims are compared in terms of each scale. There are some similarities and differences in the degree of humor among these three patterns. Before concluding, it should be mentioned that the subject's background is the key element in this regard. Of the findings which are related to humor enjoyment, age and sex differences are the most decisive factors. The ages of 15-16 are very much "Laughter-prone" (1984:124). And also women enjoy humor more than men. Although the subjects involved in this test are all female, but the other factors affect the understanding of humor as well. These important factors are; linguistic ability cognitive ability (predicting, analyzing, synthesizing, memory), cultural awareness, personality (too serious, negative attitudes), and context (right time, right place). So the subjects were selected from M.A students in order to control the linguistic proficiency factor of the recipients. On the other hand we have considered the personality factor in this study by adding a questionnaire which distinguishes Extroverts from Extroverts as Introverts enjoy humor more than Introverts. In addition, by providing the factors such as (MT, SL, FL) in the background information, we tended to control cultural aspects which can affect the results. Overall we can claim that the violation of these three different combinations of maxims leads to little humorous effect. However, the results would have been more valid if we had had plenty of subjects provided with plenty of jokes.

\section{Implications for ELT}

As the language of humor is a rich source of patterned creativity in language use, it can be widely exploited for educational purposes, such as teaching and learning. In this regard, it is possible to create new instructional 
techniques, using humor, which are used not only for motivation, but also for the enhancement of learning as well. In fact, humor is employed to facilitate information acquisition. Laughter (haha!) and Learning (aha!) can go hand-in-hand, and that in many cases, laughter can liberate learning. Humor can enhance Learning and creativity. When used appropriately, humor maximizes memory. Humor serves first to capture students' attention ("tickling" their curiosity about the subject at hand), to free up their attention (by allowing for the release of stressors that might otherwise have preoccupied them) and to hold their attention (thus providing motivation and momentum for learning).Goodman (1983:4) .Thus, fun is an important motivation in language learning, in fact, the mind learns more when it enjoys. So, humor may be included in:

- Textbooks; teaching styles,

- Classroom interaction

- Classroom management

On the whole, the implications of this study will be sought in the field of E.L.T.

\subsection{Suggested Areas for Further Research}

This study, we would hope, has paved the ground for deeper studies in this area. The topics for further investigation can be suggested as follows;

- Sex differences in humor enjoyment

- The degree of humor in narrative and interactive jokes

- The effect of humor on language Learning.

\section{References}

Alexander, R. J. ( 1993). Breaking Out of the Cage: English and German Verbal Humor in a Socio-semiotic Perspective. Trier University. Germany. In: Humor Abstracts of International Conference on Humor, Grand-Douche De Luxembourg, (30 SEP - 3 OCT, 1993)

Attardo, S. (1994). Linguistic Theories of Humor. Berlin: Mouton.

Bruyn, D. (1993). The Principle of Interest in the Joke Text. Potchefstroom University for Christian higher Education In: Humor Abstracts of International Conference on Humor, Grand - Douche De Luxembourg, (30 SEP - 3 Oct, 1993).

Chiaro, D. (1992). The Language of Jokes: Analyzing verbal play. London: Rout ledge.

Culler, J. (1982). On Deconstruction: Theory and Criticism After Structuralism. Ithaca and New York, Cornell University Press. .

Good man, J. (1983). How to Get More Smile age Out of Your Life. In: P.E. McGhee and Goldstein (Ed.), Handbook of Humor Research, Vol. 1.New York: Springer.

Gusheva, J..M. (1998). Humor in Literature. In Shine Issue, Part 5, Oct NOV, 1998. (Extracted from Internet).

Haff, J. and Kline, M. (1993). Monsieur Jourdain's Bow: The Poetics of Moliere's Comic Metaphors'. In: Humor Abstracts of International Conference on Humor. Grand Douche De Luxembourg, (30 SEP30Ct, 1993).

Krushink, S. (1959). Laughter of the Centuries . Dzhepna Knjiga, Sarajevo. (Extracted from Internet).

Lyons, J. (1981). Language and Linguistics. C U P.

McGhee, P.E. (1983). The Role of Arousal and Hemispheric Lateralization in Humor. In: P.E. McGhee and J.H. Goldstein, eds., Handbook of Humor Research. Vol. I. New York: Springer.

Mills, M. (1995). Humor and Satire as Different Forms of Comedy. Australian Journal of Comedy. Vol. 1.

Nash, W.(1985).The Language of Humor. Style and Technique in Comic Discourse. London. Longman.

Pepicello, W.J. and R.W. Weisberg. (1983). Linguistics and Humor . In: P.E. McGhee and J.H. Goldstein (Eds.), Handbook of Humor Research, Vol. 1, 59-83. New York: Springer.

Raskin, V. (1985). Semantic Mechanism of Humor. Dordrecht: Reidel.

Robinson, V.M. (1983). Humor and Health. In: P.E. McGhee and J.H. Goldstein, (Eds.), Handbook of Humor Research, Vol. II. New York, Springer. 
International Journal of Applied Linguistics \& English Literature

ISSN 2200-3592 (Print), ISSN 2200-3452 (Online)

Vol. 1 No. 6; November 2012

Ruch, W.(1998). The Perception of Humor. Department of Physiological Psychology, Heinrich Heine University of Düsseldorf, Germany (Extracted from Internet).

Suls, J.M.(1983). Cognitive Processes in Humor Appreciation. In: P.E. McGhee and J. H . Goldstein, (eds.), Handbook of Humor Research, Vol. I. 39-59. New York. Springer.

Ziv, A. (1984). Personality and Sense of Humor. Springer Publishing Company, Inc.

\section{Materials References}

Ghanbari, A.(1373). English Jokes. Rahnama Publications, Tehran,Iran.

HLT Magazine . Jokes Humanizing Language Teaching year 2: Issue 5;September 2000, from www.htlmag.co.uk/sep00/joke.htm

The Funny English Language-Brain Candy Humor Collections. Copyright 1998-2000, from corsinet.com/braincandy/hlanguage 2 . html

Ziv, A. (1984). Personality and Sense of Humor. Springer Publishing Company, New York.

\section{Appendix A}

I Background Information

Age

Gender:

Mother Tongue:

Second Language: Foreign Language:

A) In this part you will answer the following questions (just circle Yes or NO).

1. Do you like to spend a lot of time with others? Yes / No

2. Do you generally prefer reading to meeting people? Yes / No

3. Do you generally need friends to improve your mood? Yes / No

4. Do you feel uncomfortable with people who like practical jokes? Yes / No

5. When you are with other people, do you tend to talk a lot? Yes / No

6. Do you like to be yourself for long periods? Yes / No

7. Do you form friendships easily? Yes / No

8. Do you feel uncomfortable on entering a room full of strangers? Yes / No

9. Is it important to you that many people should like you? Yes / No

10. Do you avoid large groups of excited people? Yes / No

\section{Appendix B}

II. Read the following jokes, and then put an $\times$ in the appropriate column on your answer sheet to subjectively express how much humorous you find them.

1. Visitor: "How old are you, Sonny?"

Boy: "That's hard to say, Sir. According to my latest school tests, I have a Psychological age of 11 and a moral age of 10. Anatomically, I'm 7, mentally, I'm 9. But I suppose you refer to my chronological age. That's 8-but nobody pays any attention to that these days!"

2. Wife: "Have a look at the cake I decorated for my birth-day party. Don't you think my sense of design is wonderful?" Husband (counting the candles): "Yes, but your arithmetic is terrible".

3. Bride: "What do you give your husband when the dinner does not suit him?"

Mrs., Old wed : "His coat and hat."

4. "Take a bunch of flowers home for your wife, Sir." urged. the street vendor."I haven't got a wife", replied the young man. "Then buy a bunch for your sweetheart." "I don't have a sweetheart, either." "Well then buy a couple of bunches to celebrate your luck."

5. Customer: "Have you a book called 'Man, the Master of Women?"

Salesgirl: "The fiction department is on the other side, Sir."

6. Little Johnny: "Would you punish me for something I didn't do?"

Teacher: "Course not."

Little Johnny: "Well, I didn't do my homework."

7. Sailor: "Don't Bother me. I am writing to my girl." Marine : "But why are you writing so slowly?" 
International Journal of Applied Linguistics \& English Literature

ISSN 2200-3592 (Print), ISSN 2200-3452 (Online)

Vol. 1 No. 6; November 2012

Sailor: "She can't read very fast."

8. "What is your new brother's name?"

Little Jane: "I don't know yet. We can't understand a word he says."

9. "Honey", said the husband to his wife. "I invited a friend home for supper."

"What? Are you crazy? The house is a mess. I didn't go shopping. All the dishes are dirty, and I don't feel like cooking a fancy meal!" "I know all that."

"Then why did you invite a friend for supper?"

"Because the poor fool's thinking about getting married."

10. "What did you buy your husband for his birthday?"

"Well, knowing he wanted a diary, I bought him one that locked; he's so particular about his notes."

"And surely you bought something for yourself."

"Oh, yes; I bought myself a duplicate key for the diary."

11. "Aunt Mary has a new, baby," a mother told her small daughter.

"What was wrong with the old one?", answered the little girl.

12. Teacher: "Which is farther away, England or the moon?"

Johnny: "England."

Teacher: "England? What makes you think that?"

Johnny: "Because we can see the moon and we can't see England."

13. "It was so cold where we were," boasted the traveler who just returned from Alaska, "That the candle froze and we couldn't blow it out". "That's nothing," said his rival, "Where we were, the words came out of our mouths in pieces of ice, and we had to fry them to see what we were talking."

14. Movie Director: "Now here is where you jump off the cliff."

Nervous Actor: "Yeah, but suppose I get injured or killed?"

Movie Director: "Oh, that's all right. It's the last scene in the picture."

15. "Did you know that I had taken up story-writing as a career?"

"No. sold any thing yet?"

"Yes; my watch, my Saxophone and my overcoat."

\section{Appendix C}

\section{Answer Sheet}

How Much Humorous

\begin{tabular}{|c|c|c|c|c|c|}
\hline Joke NO & NO Humor & Little & Some & Much & Very Much \\
\hline 1 & & & & & \\
\hline 2 & & & & & \\
\hline 3 & & & & & \\
\hline 4 & & & & & \\
\hline 5 & & & & & \\
\hline 6 & & & & & \\
\hline 7 & & & & & \\
\hline 8 & & & & & \\
\hline 9 & & & & & \\
\hline 10 & & & & & \\
\hline 11 & & & & & \\
\hline 12 & & & & & \\
\hline 13 & & & & & \\
\hline 14 & & & & & \\
\hline 15 & & & & & \\
\hline
\end{tabular}

